\title{
Learning Competencies in Action: Tenth Grade Students' Invest- ment in Accumulating Human Capital under the Influence of the Upper Secondary Education System in Japan
}

\author{
MAtsuoKa, Ryoji*
}

\begin{abstract}
Kariya (2009) proposes a concept of learning competencies to understand how social reproduction occurs in the current context of Japanese society; he argues that students' learning competencies are not equally distributed but shaped by their family background, a foundation of unequal socioeconomic inequality. While he contends that learning competencies are "the core engine that structures and runs the accumulation and distribution of this new form of human capital" (p.111), his study does not show if students differently engage in learning activities because of their level of learning competencies. Also, he does not address any relationship between school characteristics and learning competencies. Thus, this study is designed to investigate whether students' current learning competencies, under the influence of the school system, shape their attempts in improving academic and learning skills that likely lead to the accumulation of human capital, revealing how learning competencies function in action.

By employing a nationally representative data called the Programme for International Student Assessment (PISA) 2009, four multilevel logistic regression analyses were carried out to test how school and student-level variables are related to four types of students' learning activities: attending additional lessons in mathematics outside regular lessons for enrichment and remedial purposes, studying mathematics (as opposed to not studying at all), and studying for improving their academic skills. Findings of this study show that tenth grade students' learning competencies and school's ranking shape their engagement in the learning activities. As students from high socioeconomic families are more likely to have higher learning competencies and to attend competitive schools, the Japanese high school ranking system, known as school-based tracking, functions to differentiate students' degree of engagement in learning, contributing to the unequal distribution of learning opportunities.
\end{abstract}

Keywords: learning competencies; inequality; tracking; high school; PISA

\footnotetext{
* Center for the Study of Social Stratification and Inequality (CSSI), Tohoku University e-mail: ryojim@ @awaii.edu
} 


\section{Introduction}

As societies move from industrial to postindustrial stage, it has been debated that new abilities (e.g., problem-solving skills) are required (e.g., Drucker, 1993: Honda, 2005). According to Kariya $(2008,2009)$, Japan used to be viewed as a middle class society, with an emphasis on the importance of having "academic credentials" based on a meritocratic ideology; however, there has been a shift from this type of credentials-oriented society to a type of class society that differentiates people based on their level of learning competencies that are "a combination of eagerness to learn, good learning habits, initiating active learning, and learning how to learn" (Kariya, 2009, p.94). In this new "learning capital society" (p.88), Kariya (2009) argues that "learning competencies are the core of the new types of human capital formation" (p.92), which are referred to as a form of learning capital. After emphasizing that social inequality and its reproduction over time are led by the unequal distribution of learning competencies and how crucial it is to develop learning competencies at younger ages for one's life chances, Kariya (2009) questions whether learning competencies are equally distributed based on individuals' socioeconomic backgrounds. He hypothesizes that students with disadvantages in terms of family supports and environments tend to "fall behind in developing learning competence as well as basic skills" (p.101), and then "never develop the mechanism of lifelong human capital formation" (p.101).'

According to Kariya (2009), it is possible to measure learning competencies indirectly by observing students' attitudes toward learning, and he uses regional data which includes variables that reflect "students' degree of active participation and their perception of themselves as taking responsibility for their own learning" (p.102) that are the main components of learning competencies: being able to learn how to learn. Kariya (2009) finds that fifth and eighth grade students with higher cultural backgrounds are more likely to have higher learning competencies; learning competencies are unequally distributed and significantly influenced by students' family background. These gaps in learning competencies are observed as early as the fifth grade level. He contends that disadvantaged students will "eventually face the most severe challenges in developing those competencies later in life" (p.106) because of their family environments that "limit their exposure to learning opportunities, and thus their development of adaptive, efficient and successful learning competencies" (p.110).

While Kariya (2009) insists that learning competencies are "the core engine that structures and runs the accumulation and distribution of this new form of human capital" (p.111), his study does not show if individuals differently invest in accumulating human capital because of their level of learning competencies. Also, his findings cannot be generalized, as the data is regional, and includes only sixteen public elementary schools and eleven public junior high schools. In addition, the data has limitations in terms of variables that capture one's socioeconomic status in detail. Furthermore, he does not address any relationship between school characteristics and learning competencies. This study is therefore designed to overcome these points and to add new insights to his argument of learning competencies, deepening our understanding of how and why inequality persists over generations in Japan. For this purpose, the study employs a nationally representative data of tenth grade students, as differences of high school students' engagement in learning are likely to be greater than those of fifth and eighth grade students that Kariya (2009) observed. Also, this data enables us to investigate if there is school-level effect, known as a 
tracking effect at the high school level in Japan, on students' engagement in learning activities while their learning competencies are controlled. More specifically, this study is intended to reveal if high school students' current learning competencies and the school system influence their attempts in improving academic and learning skills that are likely to shape their academic and career trajectories.

The data utilized in the study is from the Programme for International Student Assessment (PISA) 2009, which is conducted by the Organisation for Economic Co-operation and Development (OECD); 6077 tenth grade students in 185 schools are included in Japanese data set of this large scale examination. Four multilevel logistic regression analyses were carried out to test how school and student-level variables are related to four types of students' learning activities: attending additional lessons in mathematics outside regular lessons for enrichment and remedial purposes, studying mathematics (as opposed to not studying at all), and studying for improving their academic skills. These analyses will reveal if (1) learning competencies function as an engine of human capital formation and (2) the school system designed by educational policies differentiates students' engagement in learning activities.

\section{High School Ranking System in Japan}

Tracking is defined as "the process whereby students are divided into categories so that they can be assigned in groups to various kinds of classes" (Oakes, 2005, p.3). Although most U.S. high schools have become comprehensive schools due to the "detracking" movement, the structure of tracking remains; high schools still sort students into different classes within schools (Lucas, 1999). A recent case study by Heck, Price and Thomas (2004) also confirms that while no formal tracking exists in a comprehensive high school, there are course-taking patterns based on the difficulty of courses in a hierarchical order, that is analogous with the tracking structure. Negative effects of tracking are segregation, low social status, heterogeneous tracks, slower achievement of students in low tracks and negative social psychological consequences (Hallinan, 1994). As students from lower socioeconomic families are likely to be placed in lower tracks, tracking based on academic performance is one of the core structural mechanisms which reinforces and intensifies existing inequality in schooling (Oakes, 2005).

In Japan, upper secondary schools are ranked on a single continuum, even though there is no specific word for "tracking" in Japanese (LeTendre, Hofer, \& Shimizu, 2003). After passing high school entrance examinations and graduating from middle school, students attend upper secondary schools that correspond with their academic performance (Rohlen, 1983). This type of differentiation has been recognized as a hierarchical academic ranking system (e.g., Kariya \& Rosenbaum, 1999) similar to tracking. Kariya's recent study (2011) confirms that this system still exists.

Effects of this academic ranking structure have been examined in Japan and tracking studies have revealed the following: (1) students' tracking position is related to their family background; those with higher socioeconomic status (SES) tend to enter top ranked schools (e.g., Nakanishi, Nakamura, \& Ouchi, 1997; Yamamoto \& Brinton, 2010); this is especially clear in competitive private schools (Kariya, 2011); (2) students' tracking position (school rank) influences their postsecondary aspirations (e.g., Honda, 2009; Taki, 2011). This tendency is observed even before students began to attend high school, once they had known which upper secondary school they 
would attend (Kariya \& Rosenbaum, 1987); (3) general education-schools (futsuka) offer different academic contents in lessons, based on their school rank (Kikuchi, 1986); (4) there are relationships between school rank and characteristics of schools such as student culture, morale and discipline (e.g., Knipprath, 2010); (5) school rank is related to whether high school students are internally motivated to study (Aramaki, 2002), and (6) students who attended low ranked schools rarely succeed to enter competitive higher education institutions (Nakanishi, 2000; Ono, 2001). In essence, students who attend low-ranked general/vocational high schools "are virtually eliminated from further competition for higher education" (Kariya and Rosenbaum 1987, p.178), while " $[\mathrm{a}]$ ttending higher ranking high schools significantly improves the probability of advancing to higher ranking colleges" (Ono 2001, p.182). Onai (1998), therefore, argues that the Japanese high school system functions to reproduce the existing inequality. It is important to note that, two studies (Hida, Mimizuka, Iwaki, \& Kariya, 2000; Ojima, 2001) examine the tracking system's changes over two points of time, and they report no significantly changes in terms of the ranking system and its effects. Furthermore, a recently conducted study by Kariya (2011) indicates that for a younger cohort, whose average age is around 23.5 at the time of the survey, students who attend selective private schools are likely to enter competitive universities, compared to those from selective public schools, while high SES students tend to be enrolled in the private schools.

\section{Research Question}

Given Kariya's argument on learning competencies and the tracking literature, the research question of this study is "do students' learning competencies and their tracking position (school ranking) influence their learning activities?" A hypothesis of this study is that (1) students with higher learning competencies and (2) those in highly ranked schools are more likely to engage in learning activities, widening socioeconomic-based inequality through differentiated learning activities outside of regular lessons. An underlying mechanism of this growing inequality is that students from high socioeconomic background are likely to have higher ability in academic subjects and they gain higher learning competencies through, as Kariya (2009) argues, early family socialization, and subsequently their relatively higher learning competencies trigger students to seek out further learning opportunities in forms of additional lessons and self-studying. In other words, it is hypothesized that students' high learning competencies lead to their investment in accumulating capital which would advance their positioning in the academic race to gain admission to competitive higher education institutions. This could be the mechanism of how students from families with high socioeconomic status who attend competitive high schools tend to successfully enter selective universities, in addition to the well-documented relationship between students' socioeconomic background and achievement.

\section{Method}

\subsection{Data}

This study utilizes the Japanese dataset of PISA 2009 conducted by OECD. It includes results of written examinations on a randomly drawn sample of fifteen-year-old students along with family and school-contextual information based on student and principal questionnaires. 
PISA 2009 was implemented at randomly sampled high schools in the third or fourth month of the academic year in Japan (National Institute for Educational Policy Research, 2010). A twostage cluster sampling method was taken to obtain the sampled schools. First, high schools were categorized into four segments: academic public high schools, vocational public high schools, academic national/private high schools, and vocational national/private high schools. After schools were randomly selected with a specific number of students that would proportionally reflect the cohort nationwide in each segment, tenth grade students (high school freshmen) were randomly drawn from these schools. This resulted in an average of 33 students at each school that took the test, which totaled 6077 tenth grade students in 185 high schools.

It is critical to emphasize that, as Knipprath (2010) argues, "PISA data in Japan are more suitable to study the issue of tracking than of school effectiveness" (p.403). Since the sampled students had been at their schools for only three or four months, it is reasonable to assume that there is little or no school-effects on students' performance (i.e., test scores), while it is likely that school rank has shaped whether students engage in learning activities outside of regular lessons (e.g., attending additional lessons), which is what this study investigated.

\subsection{Dependent variables}

The current study employs four dichotomous dependent variables to examine four aspects of students' learning activities. These dependent variables were created based on items on the student questionnaire by OECD (2008) and the sampled students' responses to them. Mathematics was selected among three subjects (i.e., language, mathematics and science) tested in PISA, as it is (1) a required subject at the tenth grade and (2) the most studied subject by tenth grade students in the forms of additional enrichment/remedial lessons and self-studying, according to a preliminary descriptive analysis of PISA2009-data. This helps capture as many students studying outside regular lessons as possible.

Attending additional enrichment course(s) in mathematics. To create this dichotomous variable, I coded students' responses to Q31. The original item was written as follows. "What type of < out-of-school-time lessons> do you attend currently? These are only lessons in subjects that you are also learning at school, that you spend learning extra time outside of normal school hours. The lessons may be given at your school, at your home or somewhere else." (OECD, 2008, p.19). The students were asked to select either "yes" or "no" for nine items. Students who reported "yes" for "b) $<$ Enrichment lessons $>$ in $<$ mathematics $>$ " was coded as 1 and those chose "no" for this item was shown as 0 . This variable should indicate if students attend additional lessons for enriching their academic performance in mathematics. It should be noted that these extra lessons may be offered by school teachers as hoshu (free-of-charge additional lessons at school), by yobiko (shadow education-institutions that students pay for) and/or by private tutors. In these lessons, students likely learn beyond what they study in regular lessons.

Attending additional remedial course(s) in mathematics. This variable shows whether students take extra lessons for remedying their performance in mathematics. This was based on students' responses to "f) $<$ Remedial lessons $>$ in $<$ mathematics $>$ " of Q31 "What type of $<$ outof-school-time lessons $>$ do you attend currently?" (OECD, 2008, p.19). Tenth grade students who chose "yes" were indicated as 1 and those who selected "no" were shown as 0. Students take these courses, as they probably need opportunities to catch up what they learn in regular lessons.

Studying mathematics. This variable was created to identify students who engage in studying mathematics, as opposed to those who do not study the subject at all. This is the reverse-coded 
variable of "no study-kids" that Kariya (2004) defines; he argues that no-study-kids depend on regular school-lessons, as they do not attend (or cannot afford to go to) shadow education institutions (e.g., cram schools: afterschool-paid-lessons) and spend no time studying academic subjects by themselves. To identify students who study math outside regular lessons in some forms, I used students' responses to Q32 which was translated into "how long do you study the following subjects per week outside of regular lessons." Students who selected "none at all" was coded as 0 , and all other students who engage in studying math were indicated as 1 to represent students who study math outside of regular lessons. In other words, this variable represents who is not "no study-kid." According to a descriptive analysis, $23.3 \%$ of students do not study mathematics outside regular lessons. ${ }^{3}$

Studying for improving academic achievement. This variable was constructed based on students' responses to "i) Lessons to improve your < study skills> (OECD, 2008, p.19)" of Q31 regarding out-of-school-time lessons. It should be noted that this was translated differently into Japanese; a re-translated version of this phrase should read "studying for improving academic achievement."

\subsection{Independent variables}

There are four explanatory variables at the student-level: Student SES (socioeconomic status), Student Math Score (as academic performance), LC (Learning Competencies) and Female (Gender). As for school level, there are five variables in each model: School Rank (tracking location), General/Vocational Education, Private/Public and two variables that indicate city size (two dummy variables: City and Large city). School Rank and General/Vocational Education (curriculum tracking) represent students' location in the hierarchical tracking system.

Student level variables

Student SES. The "PISA index of economic, social and cultural status" premade by the PISA team was included in models as an individual SES indicator. OECD (2012) describes that the index's components are home possession (e.g., the number of books at home), higher parental occupation (father's or mother's occupation, whichever is higher) and the higher parental education indicated as years of schooling (father's or mother's education whichever is longer).

Student Math Score (Mathematics Performance). Five plausible values in math were provided by PISA team for analyses and they should be examined simultaneously. These values represent tenth grade students' academic performance in math.

$L C$ (Learning Competencies). This index was created based on students' responses to " $\mathrm{Q} 27$ : When you are studying, how often do you do the following? (OECD, 2008, p.17)" Nine items of Q27 were selected to represent students' learning competencies, which could be measured by "students' degree of active participation and their perception of themselves as taking responsibility for their own learning" (Kariya, 2009, p.102). Five of the items are about "control strategies" that students take when studying and the other four items are intended to show their "elaboration strategies", according to OECD (2012). ${ }^{5}$ Students were asked to select "almost never", "sometimes", "often" or "almost always" for each item. Their responses were summarized through principal component analysis. ${ }^{6}$

Female (Gender). Female was indicated as 1 (48.6\%), while male counterparts were coded as 0 (51.4\%).

\section{School level variables}

School Rank. This continuous variable shows student's tracking location; students' plausible 
values in mathematics were aggregated at each school. Each plausible value was separately aggregated and standardized (mean $=0$, standard deviation $=1$ ). Each school's average value, which is normally distributed, is meant to indicate its position in the well-defined hierarchal academic ranking system.

General/Vocational Education School (Curriculum tracking). General education-schools were coded as 1 , while vocational education-schools are shown as 0 . Since schools were sampled for each general/vocational segment (National Institute for Educational Policy Research, 2010), every sampled school has only one curriculum, having either general education classes or vocational education classes.

Private/public School. Private schools are shown as 1 and public counterparts are indicated as 0 .

School City Size. One item in the school questionnaire filled out by school principals indicates the size of the community in which their school is located. Two dummy coded variables were created based on school principals' responses to this item.

\section{Analysis}

Four multilevel logistic regression analyses were carried out to test whether students' learning competencies and school ranking shape their four types of learning activities outside regular lessons. Three models were made with each dependent variable: (1) a null model without any exploratory variable, (2) a model with student-level predictors, and (3) a model with both student and school-level variables. ${ }^{7}$

Due to space limitations, only results of Model 3 with each dependent variable are discussed in this article. Every model is a random intercept model, meaning that the variation in the levels of the intercepts was estimated to reflect between-school differences in students' learning activity. As all random slopes were insignificant, within-slopes were fixed. After theoretically meaningful cross-level interaction-terms were tested, the models were finalized. Results of all models were averaged with five plausible values (i.e., students' math score and school rank).

\section{Results}

\subsection{Descriptive statistics}

\section{Dependent variable}

Table 1 shows descriptive statistics of the four dichotomous dependent variables.

\section{Independent variables}

Continuous variables (i.e., Student SES, Math Score and Learning Competencies) were standardized in order to help interpret results of the multilevel analyses, as summarized in Table 2 .

Table 3 is a frequency table of school-level dichotomous variables. As the table shows, about $47.0 \%$ of the schools are in cities whose population ranges from ten thousand to one million people, and $21.6 \%$ are located in large cities with over one million people. The rest of the schools are in towns, smaller towns or village with populations of less than ten thousand people.

Table 4 indicates the descriptive statistics of School Rank, which is a school-level continuous variable. It was standardized $(M=0, S D=1)$ and normally distributed. 
Table 1 Four dependent variables ${ }^{8}$

\begin{tabular}{lrr}
\hline & Frequency & Valid Percent \\
\hline Attending enrichment course(s) in math (1) & 1783 & $29.6 \%$ \\
No (0) & 4239 & $70.4 \%$ \\
Missing & 55 & \\
Total & 6077 & \\
\hline Attending remedial course(s) in math (1) & 2057 & $34.2 \%$ \\
No (0) & 3966 & $65.8 \%$ \\
Missing & 54 & \\
Total & 6077 & \\
\hline Studying Mathematics (1) & 4629 & $76.7 \%$ \\
No time for studying mathematics (0) & 1405 & $23.3 \%$ \\
Missing & 43 & \\
Total & 6077 & \\
\hline Studying for improving achievement (1) & 2824 & $46.9 \%$ \\
Others (0) & 3198 & $53.1 \%$ \\
Missing & 55 & \\
Total & 6077 & \\
\hline
\end{tabular}

Table 2 Student background continuous variables 9

\begin{tabular}{cccccccc}
\hline & N & Min & Max & Mean & SD & Skewness & Kurtosis \\
\hline Student SES & 5974 & -3.59 & 3.38 & 0 & 1 & 0.00 & -0.38 \\
Math Score & 6077 & -4.73 & 2.93 & 0 & 1 & -0.24 & 0.06 \\
LC & 5990 & -1.98 & 3.25 & 0 & 1 & 0.25 & -0.11 \\
\hline
\end{tabular}

Table 3 School level-categorical variables ${ }^{10}$

\begin{tabular}{llrr}
\hline & & Frequency & Percent \\
\hline Curriculum Track & General (1) & 139 & $75.1 \%$ \\
& Vocational (0) & 46 & $24.9 \%$ \\
School Type & Private (1) & 51 & $27.6 \%$ \\
& Public (0) & 134 & $72.4 \%$ \\
City (Dummy) & City (1) & 87 & $47.0 \%$ \\
& Others (0) & 98 & $53.0 \%$ \\
Large City (Dummy) & Large City (1) & 40 & $21.6 \%$ \\
& Others (0) & 145 & $78.4 \%$ \\
\hline
\end{tabular}

Table 4 School level-continuous variable ${ }^{11}$

\begin{tabular}{cccccccc}
\hline & N & Min & Max & Mean & SD & Skewness & Kurtosis \\
\hline School Rank & 185 & -3.21 & 2.28 & 0 & 1 & 0.01 & -0.67 \\
\hline
\end{tabular}

\subsection{Correlation matrixes}

Table 5 presents the correlation matrix of student-level variables. Because of the large student sample, some of the statistically significant correlations are relatively small in size. Student SES is significantly correlated to the following: Math Score (.301), which means higher SES students have higher ability in mathematics; to LC (.233), which suggests students with higher SES have higher LC; to enrichment-course-participation (.142), which indicates that students whose SES is higher attend additional lessons to enrich their performance; to remedial course-participation (.129), which implies higher SES students attend extra lessons to remedy their performance; to 
Table 5 Correlations between Student-Level Variables ${ }^{12}$

\begin{tabular}{|c|c|c|c|c|c|c|c|c|}
\hline & SES & Math & $\mathrm{LC}$ & Female & Enrichment & Remedial & Studying & Achievement \\
\hline Student SES & 1 & $0.301 * *$ & $0.233 * *$ & $0.037 * *$ & $0.142 * *$ & $0.129 * *$ & $0.216 * *$ & $0.143 * *$ \\
\hline Math Score & & 1 & $0.316 * *$ & $-0.047 * *$ & $0.090 * *$ & $0.073 * *$ & $0.293 * *$ & $0.174 * *$ \\
\hline $\mathrm{LC}$ & & & 1 & $-0.049 * *$ & $0.209 * *$ & $0.165 * *$ & $0.304 * *$ & $0.291 * *$ \\
\hline Female (1) & & & & 1 & $-0.026 *$ & $0.049 * *$ & $0.101 * *$ & 0.02 \\
\hline Enrichment (1) & & & & & 1 & $0.297 * *$ & $0.230 * *$ & $0.307 * *$ \\
\hline Remedial (1) & & & & & & 1 & $0.275 * *$ & $0.238 * *$ \\
\hline Studying Math (1) & & & & & & & 1 & $0.304 * *$ \\
\hline Achievement (1) & & & & & & & & 1 \\
\hline
\end{tabular}

$* * \mathrm{p}<0.01, * \mathrm{p}<0.05$

studying-math (.216), which suggests that students with higher SES study mathematics outside regular lessons; and to "achievement" (.143), which means high SES students study to improve their academic achievement.

In addition to these relationships, Math Score and LC are significantly related to the four aspects of students' engagement in learning activities respectively, suggesting that students with higher math score and higher LC participate in additional lessons, learn math and study for improving academic skills. Due to space limitations, the correlation matrix of school-level variables is not shown here. A notable correlation between them is the significant positive relationship between curriculum track and school rank (.258), which indicates that general curricular schools are significantly higher in school rank, which is consistent with the literature.

\subsection{Multilevel analyses}

\section{Model 3: Attending enrichment course(s) in mathematics}

Table 6 presents the results of Model 3 whose dependent variable is "attending enrichment course(s) in mathematics." Higher SES students tend to attend additional lessons to enrich their performance, while the other variables in the model are being held constant. Specifically, a 1-SD increase in Student SES increases the odds of taking enrichment course(s) by a factor of 1.143. Students with higher math score are less likely to do so $(\mathrm{OR}=0.856, p<.001)$. LC is also significant; a 1-SD increase in LC increases the odds of attending enrichment course(s) in math by a factor of 1.458. Turning attention to the school-level variables, School Rank, General Education and Private are positive significant predictors of the probability that students gain additional learning opportunities to enrich their performance in math. Findings of this analysis show that a 1-SD increase in School Rank increases the odds of taking enrichment course(s) by a factor of 1.34, while other variables in the model are held constant. This represents a $34 \%$ increase in the odds of gaining enrichment learning opportunities. General Education also increases the odds of attending enrichment courses; when students attend general-educationschools, the odds of obtaining additional enrichment lessons are increased by $35.3 \%$. Students attending private schools are also more likely to take extra lessons to enrich their math performance $(\mathrm{OR}=1.581, p<.001)$.

\section{Model 3: Attending remedial course(s) in mathematics}

Table 6 shows that Student SES is insignificant, while Math Score and LC at student level and School Rank and General Education at school level are significant predictors. More specifically, low math performers $(\mathrm{OR}=0.878, \mathrm{p}<.001)$ and high $\mathrm{LC}$ students $(\mathrm{OR}=1.382$, $p<.001)$ are more likely to attend remedial lessons in math. Students attending higher ranked 
schools tend to gain remedial learning opportunities; the result suggests that a 1-SD increase in School Rank is associated with a 1.218 increase in odds of students obtaining extra lessons to remedy their performance, compared with those attending schools of average academic standing in the population, holding other variables in the model constant. If students attend schools ranked 2-SD above the mean (which is the top 2-3\%-schools), the odds of taking remedial lessons are increased by roughly 1.48 times $(1.218 \times 1.218=1.484)$, or about $48 \%$, while the other variables including the curriculum track (general/vocational education) are held constant.

Model 3: Studying mathematics and Model 3: Studying for improving achievement

Similar to the above results, School Rank, General Education and Student LC are significant predictors with the two dependent variables respectively, as shown in Table 7.

Table 6 Results of Multilevel Logistic Regression Analyses ${ }^{13}$

\begin{tabular}{|c|c|c|c|c|c|c|c|c|}
\hline & \multicolumn{4}{|c|}{ M3: Attending enrichment course } & \multicolumn{4}{|c|}{ M3: Attending remedial course } \\
\hline & Coefficient & & SE & Odds Ratio & Coefficient & & SE & Odds Ratio \\
\hline \multicolumn{9}{|l|}{ School Level } \\
\hline Intercept & -1.003 & $* * * *$ & 0.155 & 0.367 & -1.262 & $* * * *$ & 0.164 & 0.283 \\
\hline School Rank & 0.292 & $* * * *$ & 0.086 & 1.340 & 0.198 & $* * * *$ & 0.064 & 1.218 \\
\hline General & 0.302 & $* * *$ & 0.128 & 1.353 & 0.728 & $* * * *$ & 0.161 & 2.071 \\
\hline Private & 0.458 & $* * * *$ & 0.114 & 1.581 & 0.166 & & 0.148 & 1.180 \\
\hline City & -0.289 & * & 0.155 & 0.749 & -0.194 & & 0.155 & 0.824 \\
\hline Large City & -0.139 & & 0.164 & 0.870 & -0.229 & & 0.167 & 0.796 \\
\hline \multicolumn{9}{|l|}{ Student Level } \\
\hline SES & 0.134 & $* * * *$ & 0.040 & 1.143 & 0.076 & & 0.055 & 1.079 \\
\hline Math Score & -0.155 & $* *$ & 0.069 & 0.856 & -0.130 & $* * *$ & 0.056 & 0.878 \\
\hline Learning Competencies & 0.377 & $* * * *$ & 0.040 & 1.458 & 0.324 & $* * * *$ & 0.042 & 1.382 \\
\hline Female & -0.170 & $* * *$ & 0.072 & 0.844 & 0.185 & $* * *$ & 0.072 & 1.203 \\
\hline \multicolumn{9}{|l|}{ Random Effect } \\
\hline Level 2 Variance & 0.248 & $* * * *$ & & & 0.348 & $* * * *$ & & \\
\hline ICC & 0.070 & & & & 0.096 & & & \\
\hline
\end{tabular}

Table 7 Results of Multilevel Logistic Regression Analyses

\begin{tabular}{|c|c|c|c|c|c|c|c|c|}
\hline & \multicolumn{4}{|c|}{ M3: Studying Mathematics } & \multicolumn{4}{|c|}{ M3: Studying for improving achievement } \\
\hline & Coefficient & & $\mathrm{SE}$ & Odds Ratio & Coefficient & & $\mathrm{SE}$ & Odds Ratio \\
\hline \multicolumn{9}{|l|}{ School Level } \\
\hline Intercept & 0.981 & $* * * *$ & 0.146 & 2.668 & -0.339 & $* * * *$ & 0.085 & 0.712 \\
\hline School Rank & 0.985 & $* * * *$ & 0.061 & 2.678 & 0.390 & $* * * *$ & 0.039 & 1.477 \\
\hline General & 0.855 & $* * * *$ & 0.159 & 2.352 & 0.213 & $* * *$ & 0.084 & 1.238 \\
\hline Private & 0.211 & & 0.134 & 1.236 & 0.022 & & 0.082 & 1.022 \\
\hline City & -0.251 & & 0.165 & 0.778 & 0.015 & & 0.089 & 1.015 \\
\hline Large City & -0.393 & $* *$ & 0.185 & 0.675 & -0.021 & & 0.102 & 0.979 \\
\hline \multicolumn{9}{|l|}{ Student Level } \\
\hline SES & 0.092 & & 0.057 & 1.096 & 0.075 & & 0.051 & 1.078 \\
\hline Math Score & 0.041 & & 0.064 & 1.043 & 0.012 & & 0.056 & 1.012 \\
\hline Learning Competencies & 0.672 & $* * * *$ & 0.052 & 1.958 & 0.524 & $* * * *$ & 0.046 & 1.689 \\
\hline Female & 0.346 & $* * * *$ & 0.090 & 1.414 & 0.078 & & 0.065 & 1.081 \\
\hline \multicolumn{9}{|l|}{ Random Effect } \\
\hline Level 2 Variance & 0.334 & $* * * *$ & & & 0.058 & $* * * *$ & & \\
\hline ICC & 0.092 & & & & 0.017 & & & \\
\hline
\end{tabular}


These results show that higher LC students and those who attend higher ranked schools and general education schools tend to study mathematics (not to become no study-kids) and to study for improving their academic skills outside of regular school-lessons. It should be noted that Math Score is not significant; students' performance is not related to whether students engage in studying, when the other variables are controlled.

\section{Discussion}

The findings of this study empirically support the hypothesis; students' LC and School Rank shape whether they engage in learning activities outside regular lessons. There is also a statistically significant relationship between Student SES and LC, as the correlation matrix shows. These results, based on the nationally representative sample, support the findings and argument by Kariya (2009); LC is unequally distributed and related to students' family SES, in addition to the unequal distribution of academic performance, which is also related to students' SES. Additionally, the results of the four multilevel logistic analyses consistently show that LC is the significant predictor in students' attempts to invest in improving academic skills in mathematics and in general (i.e., studying for improving academic achievement), while Student SES is only significant with "attending enrichment course(s)."

It should be highlighted that Student's SES matters when it comes to obtaining additional enrichment courses which are likely to be offered by shadow education institutions (i.e., yobiko and $j u k u$ ). As students need to pay for the extra lessons, Student SES (which was measured by their family's home possession, the number of books at home, and parental occupation and academic credentials) plays a role. High SES students' parents are likely to value academic success and have economic means to invest in their child's education. It is also critical to understand why "Private" is a significant school-level predictor, as this result appears to be consistent with the finding by Kariya (2011); students at competitive private high schools tend to gain admission to selective universities, compared with counterparts attending top-level public high schools. This trend could be partly explained by the findings of this study-attending private schools facilitates students to take additional learning opportunities outside of regular lessons in order to enrich their performance in the third or fourth month of the three year-high school education. It seems they already begin preparing for university entrance examinations because of attending private schools.

Contrary to the results for attending "enrichment" lessons, Student SES is not significantly correlated to "attending remedial course(s) in math." It is probably because many of these additional remedial lessons are offered by their schools for free (hoshu). ${ }^{14}$ It is important to emphasize that LC is the significant predictor for both models; whether students have a positive attitude and attempt to be responsible for their own learning influences their participation in these additional learning opportunities. Teachers may require students to attend these remedial lessons, but they tend to select high LC students, as they are "motivated" to study. Students' LC also predicts if students become studying-kids (not to be no study-kids) and study for improving their academic skills, while Student SES (which essentially means Students' family SES) is not a significant predictor. In addition, it is critical to emphasize the role of the high school-tracking system; School Rank and General Education (as opposed to vocational school) shape if students are exposed to more learning opportunities (i.e., attending additional lessons) and engage in 
studying activities at the early stage of high school education. Ultimately, the academic ranking structure appears to differentiate students' learning activities outside of regular lessons, even when curriculum tracking (General or vocational education) is controlled. ${ }^{15}$

\section{Implications}

The findings of this study emphasize that students' LC plays a role in unequal distribution of learning opportunities through their engagement in the four types of learning activities. Also, the tracking system shapes students at competitive schools to engage in learning activities outside of regular lessons, which are meant to enrich/remedy/improve their academic skills, foundations of human capital. This means that the current upper secondary education-system accelerates the cycle of unequal accumulation of human capital. While there are students engaging in these learning activities, $23.3 \%$ of the sampled students do not study mathematics outside regular lessons; they do not even do homework. These students are likely to be from low SES families, have low LC and academic performance, and attend low ranked vocational high schools. Due to the educational reproduction effects of the school ranking, it is hard to imagine that students will suddenly improve their LC and start engaging in learning activities. These results call for reconsideration of educational policies like "Super English Language High School", which provides additional resources for competitive general education-schools. As students who attend these schools are likely to be from high SES familes and already have high LC, the policy seems to only benefit already-advantaged students, widening the achievement gap.

From a broader standpoint, the tracking effects on students' engagement in learning activities are important to identify, especially now when neo-liberal policies are becoming prevalent. Policies such as school choice emphasize students' and/or parental choices and self-responsibility for the consequences of educational choices, even though students' choice is shaped by individuals' LC and tracking location (school ranking) in the educational system. The tracking system and its effect on social agents exacerbate the existing social inequities in educational opportunities outside of school educational activities (regular lessons) whose quality and quantity are also different based on schools' specific academic ranking.

In conclusion, this study reveals that high school students' LC influences their degree of investment in human capital formation by engaging (or disengaging) in learning activities, while the school ranking structure encourages those who are from high SES families and already have higher LC to further their attempts at accumulating more human capital. These results support Kariya's (2009) argument that LC functions as an engine of human capital formation, and they underscore the importance of developing learning competencies at an early stage of life. Furthermore, the findings of the study call for educational policies that reduce not only the achievement gap but also the gap in students' learning competencies.

\section{Notes}

1. Kariya (2008) refers to human capital as a general term in economics. Gary Becker (2002), the leading proponent of human capital, writes that human capital means "the knowledge, information, ideas, skills, and heath of individuals" (p.3) and contends individuals' economic success is dependent on how much they invest in themselves. As human capital has become much more important for the past two decades, it is necessary for individuals "to invest in themselves during their whole lives (p.8)" in "human capital or a knowledge capital economy" (p.3). 
2. The translated version of the questionnaire was published by National Institute for Educational Policy Research (2010).

3. According to PISA 2006, 21.4\% of tenth grade students are considered as no study-students (Matsuoka, 2013). This percentage of no study-students is the largest among those of 57 PISA-participating educational systems in the world; Japan has the largest percentage of no study-students at the age of 15 year-old.

4. See National Institute for Educational Policy Research (2010, p.264).

5. The five items about "control strategies" are "b) I start by figuring out what exactly I need to learn", "f) I check if I understand what I have read", "i) I try to figure out which concepts I still haven't really understood", "k) I make sure that I remember the most important points in the text", and " $m$ ) When I study and I don't understand something, I look for additional information to clarify this." As for "elaboration strategies", the four items are "d) I try to relate new information to prior knowledge acquired in other subjects", "h) I figure out how the information might be useful outside school", "j) I try to understand the material better by relating it to my own experiences", "l) I figure out how the text information fits in with what happens in real life."

6. Results do not change when only "elaboration strategies" or "control strategies" are included in the models.

7. As an example of models, the model 3 is shown as follows.

Level-1 Model

Probability (Dependent Variable $\left.{ }_{\mathrm{ij}}=1\right)=\phi_{\mathrm{ij}}$

$\log \left[\phi_{\mathrm{ij}} /\left(1-\phi_{\mathrm{ij}}\right)\right]=\eta_{\mathrm{ij}}$

$\eta_{\mathrm{ij}}=\beta_{0 \mathrm{j}}+\beta_{1 \mathrm{j}}\left(\right.$ Student SES $\left._{\mathrm{ij}}\right)+\beta_{2 \mathrm{j}}\left(\right.$ Math Score $\left._{\mathrm{ij}}\right)+\beta_{3 \mathrm{j}}\left(\right.$ Learning Competencies $\left._{\mathrm{ij}}\right)+\beta_{4 \mathrm{j}}\left(\right.$ Female $\left._{\mathrm{ij}}\right)$ Level-2 Model

$\beta_{0 \mathrm{j}}=\gamma_{00}+\gamma_{01}\left(\right.$ School Rank $\left._{\mathrm{j}}\right)+\gamma_{02}\left(\right.$ General Education $\left._{\mathrm{j}}\right)+\gamma_{03}\left(\right.$ Private $\left._{\mathrm{j}}\right)+\gamma_{04}\left(\right.$ City $\left._{\mathrm{j}}\right)+\gamma_{05}\left(\right.$ Large City $\left._{\mathrm{j}}\right)+\mathrm{u}_{0 \mathrm{j}}$ $\beta_{1 \mathrm{j}}=\gamma_{10}, \beta_{2 \mathrm{j}}=\gamma_{20}, \beta_{3 \mathrm{j}}=\gamma_{30}, \beta_{4 \mathrm{j}}=\gamma_{40}$

8. Final student weight was not used for this presentation to show how 6077 sampled students are distributed.

9. Final student weight and replicate weights were used. "Math Score" presented in the table is based on plausible value 1 in math.

10. No school weight was used for this presentation to describe how 185 sampled schools are distributed.

11. "School Rank" in this table is an average of students' plausible value 1 in math.

12. For this presentation, correlations of the five school-rank-variables (school-average of each plausible value) were averaged.

13. Final student weight and school weight were used when multilevel analyses were carried out. Replicates weight were also used to test if results would significantly change.

14. One may argue that students are required by their teachers to attend extra school lessons (hoshu) for mostly for remedial purposes. This may apply to some cases, but, as LC is the positive predictor, teachers may selectively require specific students who demonstrate higher motivation for taking additional lessons, and these relatively higher LC-students tend to have higher SES. This still can be considered an issue of inequality.

15. As no interaction effects were found, these school-level effects remain as addictive effects. Thus, it could be argued that the tracking system does not discriminate against low SES students, as these disadvantaged students could benefit from the tracking effect when they successfully enter competitive high schools despite their family background. The tracking structure is purported to assist this smaller number of students who are from low SES family but who also attend higher ranked schools to engage in learning activities.

O This work was supported by the Center for the Study of Social Stratification and Inequality at Tohoku University under the Global COE Program and by JSPS KAKENHI Grant Number 24830009.

\section{References}

Aramaki, S. (2002). Gendai kokosei no gakusyu iyoku to sinro kibo no keisei: Syussin kaiso to kachisiko no koka ni tyumoku site [Learning attitudes and educational expectations of current high school students: The effects of family background and value orientations]. The journal of educational sociology, 71, 5-22.

Becker, G.S. (2002). The Age of Human Capital. In E.P. Lazear (Ed.), Education in the Twenty-First Century (pp.3-8). Palo Alto: Hoover Institution Press.

Drucker, P.F. (1993). Post-Capitalist Society New York: Harpercollins.

Hallinan, M.T. (1994). Tracking: From theory to practice. Sociology of Education, 67(2), 79-84.

Heck, R.H., Price, C.L., \& Thomas, S.L. (2004). Tracks as Emergent Structures: A Network Analysis of Student Differentiation in a High School. American Journal of Education, 110(4), 321-354. 
Hida, D., Mimizuka, H., Iwaki, H., \& Kariya, T. (Eds.). (2000). Kokosei bunka to sinro keisei no henyo [High school student culture and change on career options] (Shohan. ed.). Tokyo: Gakuji Shuppan.

Honda, Y. (2005). Tagenkasuru 'noryoku' to nihon syakai: hyper-meritcracy ka no nakade (Ability to diversify and Japanese Society: in the era of hyper-meritocracy). Tokyo: NTT Shuppan.

Honda, Y. (2009). Toritsu kokosei no seikatsu kodo isiki ni kansuru tyosa hokokusyo [Report about investigating metropolitan high school students in terms of their lives, actions and feeling]. 22-33. Retrieved from http://benesse.jp/berd/center/open/report/toritsu_kousei/2009/pdf/data_04.pdf

Kariya, T. (2004). Gakuryoku no kaisosa ha kakudai shitaka [Is disparity of academic achievement based on social class widen?] In T. Kariya \& K. Shimizu (Eds.), Gakuryoku no shakaigaku: Chosa ga shimesu gakuryoku no henka to gakushu no kadai [Sociology of academic achievement: changes of academic achievement and problems of learning shown by surveys] (pp.vii, 299p.). Tokyo: Iwanami Shoten.

Kariya, T. (2008). Gakuryoku to kaiso [Academic achievement and social class]. Tokyo: Asahi Shinbun Publications Inc.

Kariya, T. (2009). From credential society to "learning capital" society: A rearticulation of class formation in Japanese education and society. In H. Ishida \& D. H. Slater (Eds.), Social class in contemporary Japan: Structures, sorting and strategies (pp.87-113). New York: Routledge.

Kariya, T. (2011). Japanese solutions to the equity and efficiency dilemma? Secondary schools, inequity and the arrival of 'universal' higher education. Oxford Review of Education, 37(2), 241-266.

Kariya, T., \& Rosenbaum, J.E. (1987). Self-Selection in Japanese junior high schools: A longitudinal study of students' educational plans. Sociology of Education, 60(3), 168-180.

Kariya, T., \& Rosenbaum, J.E. (1999). Bright flight: Unintended consequences of detracking policy in Japan. American Journal of Education, 107(3), 210-230.

Kikuchi, E. (1986). Tyuto kyoiku ni okeru tracking to seito no bunka katei [Differentiation and tracking in secondary education]. The journal of educational sociology, 41, 136-150.

Knipprath, H. (2010). What PISA tells us about the quality and inequality of Japanese education in mathematics and science. International Journal of Science and mathematics Education, 8(3), 389-408.

LeTendre, G. K., Hofer, B. K., \& Shimizu, H. (2003). What Is Tracking? Cultural Expectations in the United States, Germany, and Japan. American Educational Research Journal, 40(1), 43-89.

Lucas, S.R. (1999). Tracking inequality: stratification and mobility in American high schools. New York: Teachers College Press.

Matsuoka, R. (2013). Comparative analysis of institutional arrangements between the United States and Japan: Effects of socioeconomic disparity on students' learning habits. Hikaku kyoikugaku kenkyu [Comparative education studies ], 46, 3-20.

Nakanishi, Y. (2000). Gakko rank to syakai ido [School rank and social mobility]. In H. Kondo (Ed.), Nihon no kaiso shisutem 3: Sengo nihon no kyoiku syakai [Japanese social stratification system 3: Education in postwar Japan]. Tokyo: Tokyo Daigaku Shuppankai.

Nakanishi, Y., Nakamura, T., \& Ouchi, H. (1997). Sengo nihon no kokokan kakusa seiritsu to syakai kaiso: 1985 nen SSM cyosa data no bunseki wo tsujite [High school streaming and social stratification in post-war Japan: Analyzing the data set of the 1985 SSM national survey]. The journal of educational sociology, 60, 61-82.

National Institute for Educational Policy Research (Ed.). (2010). Ikiru tame no chishiki to gino 4: OECD seito no gakusyu totatsudo cyosa (PISA) (2009nen cyosa kokusai kekka hokokusyo) [Knowledge and skill for living 4: OECD Programme for International Student Assessment (PISA) (report on international results of the survey in 2009). Tokyo: Akashi syoten.

Oakes, J. (1985). Keeping track: how schools structure inequality. New Haven: Yale University Press.

Oakes, J. (2005). Keeping track: how schools structure inequality (2nd ed.). New Haven, Conn.; London: Yale University Press.

OECD. (2008). Student questionnaire for PISA 2009: main survey Retrieved July 28th, 2012, from http:// pisa2009.acer.edu.au/downloads/PISA09_Student_questionnaire.pdf

OECD. (2012). PISA 2009 Technical Report Retrieved from http://www.oecd.org/document/19/0,3746, en_2649_35845621_48577747_1_1_1_1,00.html.

Ojima, F. (Ed.). (2001). Gendai kokosei no keiryo syakaigaku: shinro, seikatsu, and sedai [Sociometry of high school students: career options, life, generation]. Kyoto: Minerva shobo.

Onai, T. (1998). Kogyo syuseki tiiki ni okeru kokokan kakusa to kokosei no seikatsu isiki [Disparities among high schools and Students' lives and attitude in industrial complexes-area]. Cyosa to Syakai riron [Research and Social Theory] Retrieved October 15th, 2009, from http://eprints.lib.hokudai.ac.jp/dspace/handle/2115/ 22575 . 
Ono, H. (2001). Who goes to college? features of institutional tracking in Japanese higher education. American Journal of Education, 109(2), 161-195.

Rohlen, T.P. (1983). Japan's high schools. Berkeley: University of California Press.

Taki, H. (2011). Nihon no koko track to syakaikaiso no kanrenkozo: PISA data wo motiite [Associated structure of Japanese high school tracking and social stratification: By using PISA data]. Sociologi [Sociology] 55(3), $37-52$.

Yamamoto, Y., \& Brinton, M.C. (2010). Cultural capital in East Asian educational systems: The case of Japan Sociology of Education, 83(1), 67-83. 